
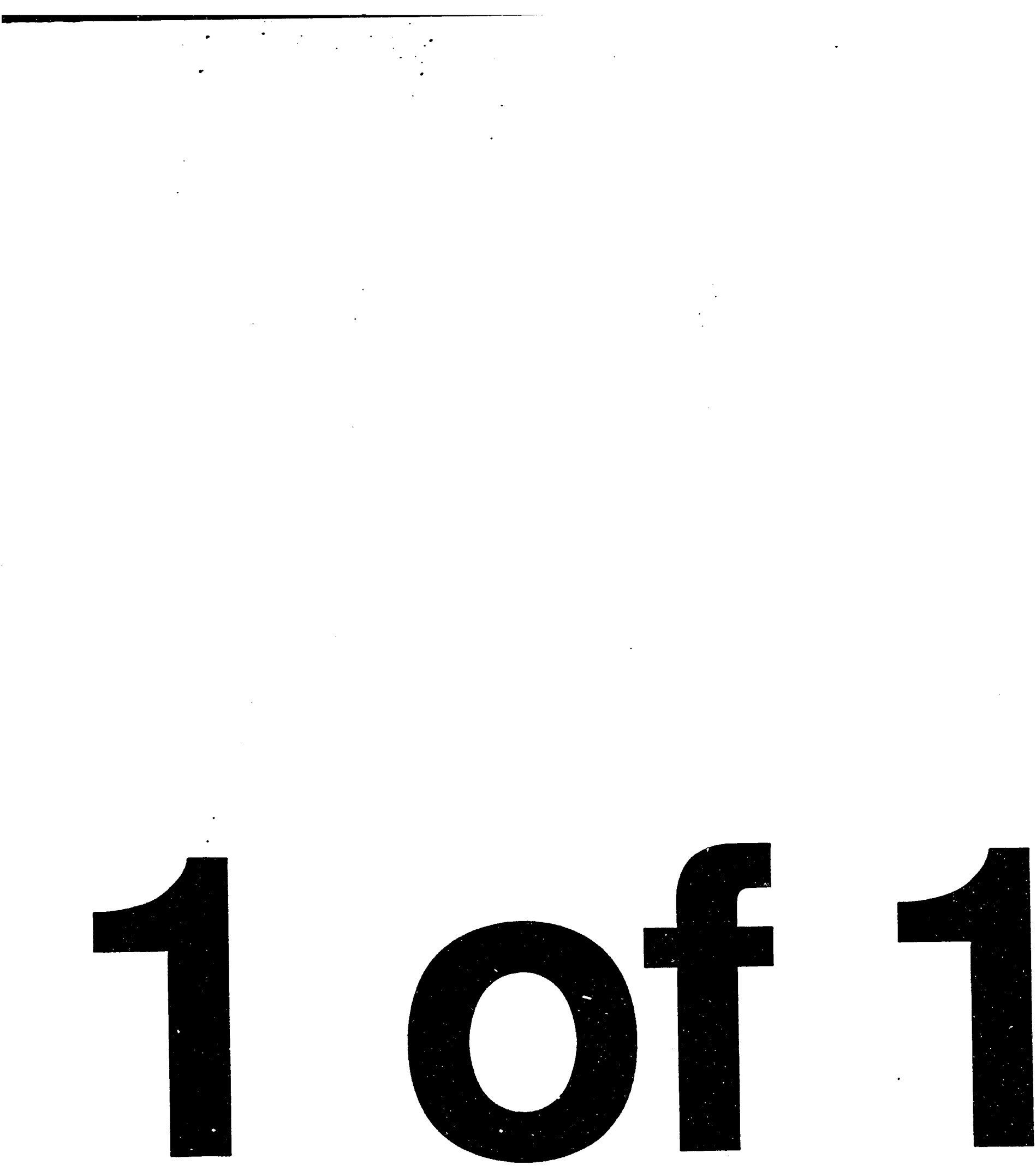


\title{
Efficiency Consideration of DC Link Soft-Switching Inverters for Motor Drive Applications
}

\author{
J. S. Lai, R. W. Young, and J. W. McKeever \\ Oak Ridge National Laboratory \\ Bldg. K-1220, M/S 7280 \\ Oak Ridge, Tennessee 37831-7280
}

TEL: (615)576-6223

FAX: (615)576-0279

Corresponding Author: Jih-Sheng Lai

Topic Code: 5

\begin{abstract}
This paper critically evaluates efficiency of soft switching inverters including an actively clamped resonant dc link inverter and a clamped-mode resonant pole inverter. An analytical approach to evaluating efficiency of the clamped-mode soft switching inverter has been developed. The evaluation results are compared with that of the standard pulse-widthmodulation (PWM) inverter. A $50-\mathrm{kW}$ induction motor is used as the variable load, and the inverter efficiency is evaluated under different speed and torque conditions. The clamped-mode soft-switching inverter, although eliminating the switching loss, shows poor efficiency over the entire load range. Under low load conditions, the efficiency profile is even worse. The actively clamped resonant dc link inverter shows highest efficiency over the entire speed and torque range. However, its energy saving over the standard PWM inverter is marginal under full load or high speed conditions.
\end{abstract}

\section{DISCLAIMER}

This report was prepared as an account of work sponsored by an agency of the United States Government. Neither the United States Government nor any agency thereof, nor any of their employees, makes any yarranty, express or implied, or assumes any legal liability or responsibility for the accuracy, completeness, or usefulness of any information, apparatus, product, or process disclosed, or represents that its use would not infringe privately owned rights. Reference herein to any specific commercial product, process, or service by trade name, trademark, manufacturer, or otherwise does not necessarily constitute or imply its endorsement, recommendation, or favoring by the United States Government or any agency thereof. The views and opinions of authors expressed herein do not necessarily state or reflect those of the United States Government or any agency thereof. 


\title{
Efficiency Consideration of DC Link Soft-Switching Inverters for Motor Drive Applications
}

\author{
Digest
}

\section{Introduction}

Soft switching inverter configuration can be ac link or dc link, zero voltage or zero current switching. The zero-voltage dc link soft switching inverters have received more attentions because they do not need bi-directional or reverse blocking devices. There are several types of dc link soft switching inverters. One is the resonant dc link inverter which produces resonating voltage across the input of the inverter bridge, and the other is the resonant pole inverter which adds an auxiliary resonant branch for each inverter leg. The resonant dc link inverter provides a common zero voltage to all switching devices, while the resonant pole inverter produces a zero voltage for the individual device. In general the resonant link inverter has a simpler structure than the resonant pole inverter. However, the resonant link inverter restraints that all devices be switched on and off simultaneously. The resonant pole inverter, on the other hand, allows each phase independently modulated, and thus achieving higher resolution output.

When considering the efficiency, one must not assume that all soft switching inverters are more efficient than the traditional hard-switching pulse-width-modulation (PWM) inverters. The main purpose of this paper is to critically evaluate the efficiency of two commonly mentioned soft switching inverters -- actively clamped resonant dc link inverter (ACRDCL) [1 4] and clamped mode resonant pole inverter (CMRP) [5 6]. The efficiency evaluation results are then compared with those of the standard sinusoidal PWM (SPWM) inverter.

In order to evaluate the inverter efficiency, the component model and the switching algorithm must be well-defined. Because of the complexity of the device model, a precise evaluation may not be achievable without actual tests. However, by making some assumptions and simplifying device models, the evaluation can be fairly applied to different inverter topologies, and a relative performance comparison can be obtained. For conduction loss evaluation, this paper simplifies the switching device to a voltage source in series with a resistor, which is suitable for insulated gate bipolar transistors (IGBTs) and diodes. For switching loss evaluation (only applicable to SPWM inverter), a curve fitting technique is applied to find the selected device switching func: ons for both turn-on and turn-off.

The efficiency consideration for motor drive applications is somewhat different from other loads because the output power can be varied with either speed or torque. Under different 
speed and torque condizions, the motor current and power factor also affect the inverter efficiency. The variation of power factor in an ac induction machine is even more noticeable than in a permanent magnet machine. For this reason, this paper studies the inverter efficiency for a $50-\mathrm{kW}$ induction motor. Appendix A lists the motor parameters and shows the motor output characteristics. Assuming that the motor is operated with a field-oriented control, the motor current and power factor can be determined under different speed and torque conditions. The inverter efficiency is then evaluated accordingly. Evaluation results show that the ACRDCL inverter has highest efficiency over the entire load range, but the CMRP inverter has poorest efficiency because the circulating energy causes high conduction losses in the switching devices. The difference increases in low load regions. The efficiency of the hard-switching SPWM inverter is calculated here for a based line comparison.

\section{Device Models}

\subsection{Conduction Models}

In soft-switching inverters, the main losses are due to conduction, and the switching loss can be neglected in most cases. In order to determine the conduction loss, a simplified device model [6] is employed. This model assumes the device can be represented as a constant voltage drop in series with a non-linear resistive element during conduction. Due to complexity of the computation effort, this paper further simplifies the non-linear resistive element to a linear resistance in order to derive closed form solutions for conduction losses. The model parameters are extracted from the manufacturer's data sheets. Using this simplified model will not precisely predict the actual inverter efficiency; however, the simplified model provides a reasonable estimation which is fair enough for comparison purpose. The simplified models for IGBT and diode are expressed in (1) and (2) respectively,

$$
\begin{aligned}
& V_{c e}=V_{1}+I R_{c e} \\
& V_{a k}=V_{f}+I R_{a k},
\end{aligned}
$$

where $V_{c e}$ and $V_{a k}$ represent the on-state voltage drop of the IGBT and diode, $V_{t}$ and $V_{f}$ represent IGBT and diode voltage drop at zero current condition, $R_{c e}$ and $R_{a k}$ are resistive elements of IGBT and diode, and $I$ is the device current. Although real resistive elements are non-linear, this paper will assume them to be linear to simplify the analysis. The parameters $V_{c e}, V_{a k}, R_{c e}$ and $R_{a k}$ can be obtained from the manufacturer's data sheet.

\subsection{Switching Loss Models}

The efficiency evaluation of the hard-switching SPWM inverter requires switching loss model for the devices. There are three primary components in switching losses: IGBT turn-on, IGBT turn-off, and diode reverse recovery. Given a fixed dc bus voltage, the switches turn on and off energies can be represented by (3) and (4) respectively [7]. 


$$
\begin{aligned}
& E_{\text {on }}=h_{1} I^{k_{1}} \\
& E_{\text {off }}=h_{2} I^{k_{2}}
\end{aligned}
$$

Parameters $h_{l}, k_{l}, h_{2}$, and $k_{2}$ can be derived from the measured data or the manufacturer's data sheet. The diode reverse recovery not just introduces additional losses by the diode itself, but also increases the switch turn-on losses due to the recovery time. In order to represent the turnon loss model more accurately, one can either modify parameters in (3) to incorporate the recovery time effect or add an additional loss item to represent the switch loss due to the diode reverse recovery.

The diode reverse recovery loss model can be approximated with a linear recovery current wave. Equation (5) expresses the approximated diode reverse recovery energy model.

$$
E_{r r}=\left(0.5 I_{r}\right)\left(0.5 V_{s}\right)\left(t_{b}\right)
$$

where $I_{r r}$ is the peak reverse recovery current, $V_{s}$ is the dc bus voltage, and $t_{b}$ is the recovery time that has negative $d i / d t$ value.

\section{Inverter Efficiency Evaluation Methods}

\subsection{Actively Clamped Resonant DC Link Inverter}

Figure 1 shows an actively clamped resonant dc link inverter. Without active clamping, the link voltage is more than twice the supply voltage. The clamping switch $S_{c}$ circulates the energy to the clamping capacitor $C_{c}$ to reduce the link voltage to 1.3 to 1.5 times the supply voltage. The link voltage waveform using actively clamped control is shown in Figure 2. Periodical zero voltage crossing eliminates the inverter switching loss.

The loss calculation method for the ACRDCL inverter has been well discussed in literature [1][2]. The lossy components in the ACRDCL inverter include device conduction losses, active clamping device losses, and the resistive loss in the resonant inductor. The switching loss, typically representing less than $1 \%$ of the conduction loss, can be neglected in most design cases.

\subsection{Clamped Mode Resonant Pole Inverter}

Figure 3 shows a clamped mode resonant pole (CMRP) inverter. Inductor $L_{r}$ and capacitor $C_{r}$ constitute a resonant circuit. The clamping diode $D_{c}$ clamps voltage across the resonant capacitor and free-wheels the resonant current. Appendix B illustrates the operation of a single-phase CMRP inverter. The resonant circuit frequency, $f_{r}$, and characteristic impedance, $Z_{r}$, can be obtained by

$$
f_{r}=\frac{1}{2 \pi \sqrt{L_{r}\left(2 C_{r}\right)}}
$$




$$
Z_{r}=\sqrt{\frac{L_{r}}{2 C_{r}}}
$$

The resonant frequency should be much higher than the switching frequency in order to provide a wide duty cycle control.

Although the turn-on loss is zero, the turn-off loss may not be completely eliminated. With a lossless snubber capacitor across the device, the turn-off loss can be reduced to minimum, which may be negligible compared to large conduction loss. The conduction loss is a function of voltage drop, current, and duty cycle, all of which are functions of phase angle -- $\theta$, power factor angle -- $\phi$, and the device model described in the previous section.

For a bridge inverter, each half phase-leg consists of three devices that incur conduction losses. These are the switching device, the anti-parallel diode, and the clamping diode. Representing the instantaneous conduction loss as a function of the phase angle, the following three equations express conduction losses for the above three devices in a half cycle.

$$
\begin{aligned}
& p_{c-s w}(\theta)=\left(I_{r}+I_{m} \sin \theta\right)\left(V_{1}+R_{c e}\left(I_{r}+I_{m} \sin \theta\right)\right) \\
& p_{c-D}(\theta)=\frac{1}{2}\left(I_{r}+I_{m} \sin \theta\right)\left(V_{t}+R_{a k}\left(I_{r}+I_{m} \sin \theta\right)\right)(1-m \sin (\theta+\phi)) \\
& p_{c-D f}(\theta)=\frac{1}{2} I_{r}\left(V_{f}+I_{r} R_{a k}\right)(1+m \sin (\theta+\phi))
\end{aligned}
$$

where $I_{m}$ is the peak load current, $m$ is the modulation index, and

$$
I_{r}=\frac{V_{s}}{Z_{r}}
$$

The average conduction loss over the entire cycle can be obtained by integrating (8) (10) from 0 to $\pi$ and dividing them by $2 \pi$. Equations (12) through (14) show the derived average conduction losses for switch, anti-parallel diode, and clamping diode respectively.

$$
\begin{gathered}
P_{c-s w}=\frac{1}{2} I_{r}\left(V_{t}+I_{r} R_{c e}\right)+\frac{1}{4} i_{m}^{2} R_{c e}+\frac{1}{\pi} I_{m}\left(V_{t}+2 I_{r} R_{c e}\right) \\
P_{c-D}=\frac{I_{r}}{4}\left(V_{f}+I_{r} R_{a k}\right)+\frac{I_{m}^{2}}{8} R_{a k}+\frac{I_{m}}{2 \pi}\left(V_{f}+2 I_{r} R_{a k}\right)-m \cos \phi\left[\frac{I_{r}}{2 \pi}\left(V_{r}+I_{r} R_{a k}\right)+\frac{I_{m}}{8}\left(V_{f}+2 I_{r} R_{a k}\right)+\frac{I_{m}^{2}}{3 \pi} R_{a k}\right] \\
P_{c-D f}=\left(\frac{1}{4}+\frac{m \cos \theta}{2 \pi}\right) I_{r}\left(V_{f}+I_{r}^{2} R_{a k}\right)
\end{gathered}
$$

\subsection{A Standard Hard-Switching SPWM Inverter}

The efficiency calculation method of the standard hard switching SPWM inverter has been well-defined in literature [7]. Using simplified device models, the switch and diode conduction losses for each switch-pair can be obtained below. 


$$
\begin{aligned}
& P_{c-s w}=\frac{1}{2} I_{m} V_{t}\left(\frac{1}{\pi}+\frac{m}{4} \cos \phi\right)+I_{m}{ }^{2} R_{c e}\left(\frac{\sqrt{3}}{8 \sqrt{\pi}}+\frac{m}{3 \pi} \cos \phi\right) \\
& P_{c-D}=\frac{1}{2} I_{m} V_{f}\left(\frac{1}{\pi}-\frac{m}{4} \cos \phi\right)+I_{m}{ }^{2} R_{a k}\left(\frac{\sqrt{3}}{8 \sqrt{\pi}}-\frac{m}{3 \pi} \cos \phi\right)
\end{aligned}
$$

Using (3) and (4), the switching losses for the switch and the diode are obtained below.

$$
\begin{gathered}
P_{s w-o n}=\frac{1}{2 \sqrt{\pi}} f_{s} h_{1} I_{m}^{k_{1}} k_{g-o n} \frac{V_{s} \frac{\Gamma\left(\frac{k_{1}+1}{2}\right)}{V_{o}} \Gamma\left(\frac{k_{1}}{2}+1\right)}{P_{s w-n f}=\frac{1}{2 \sqrt{\pi}} f_{s} h_{2} I_{m}^{k_{2}} k_{g-o f} \frac{V_{s}}{V_{o} \frac{\Gamma\left(\frac{k_{2}+1}{2}\right)}{\Gamma\left(\frac{k_{2}}{2}+1\right)}}}
\end{gathered}
$$

where $f_{s}$ is the switching frequency, $V_{o}$ is the nominal voltage that determines the parameters $h_{l}$, $k_{l}, h_{2}$, and $k_{2}, \Gamma$ is the gamma function, $k_{g-o n}$ and $k_{g-o f f}$ are correction factors for different gate drives (choosing 1 for stiff gate drives), and $V_{s}$ is the dc bus supply voltage. The average power loss due to the diode reverse recovery can be obtained by simply multiplying (5) with the switching frequency.

\section{Performance Comparison}

Figures 4 6 show the efficiency evaluation results for the three above-mentioned inverters under different speed and torque conditions. Consider the efficiency profile of the SPWM inverter as the base line. The ACRDCL inverter shows a better efficiency profile. Under different torque conditions, in low speeds, the improvement is about $5 \%$, and in high speeds, the improvement is approximately 1 to 2 percent. The soft switching CMRP inverter, unfortunately, performs poorly in terms of efficiency consideration. At low output conditions (either low speed or low torque), its efficiency is approximately 20 percent lower than that of the SPWM inverter, and at high output conditions (high speed and high torque), is about 8 percent less efficient.

Table 1 compares the efficiency and loss separation for the three aiove-mentioned inverters at the rated output. Both SPWM and CMRP inverters operate at $20 \mathrm{kHz}$, and the ACRDCL is designed at $65-\mathrm{kHz}$ resonant frequency, actual switching frequency depends on the over-voltage setting and the load conditions. Consider a $240-\mathrm{V}$ ac line system, $600-\mathrm{V}$ device should be sufficient for both CMRP and SPWM inverters. In this study a 600-V, 600-A IGBT module has been used. The ACRDCL inverter requires a higher voltage device because the peak voltage will exceed $600 \mathrm{~V}$ during the regenerative operation which may produce as much as 20 percent over-voltage. The conduction loss of ACRDCL is thus higher than that of SPWM inverter because it uses a higher voltage rating device model $1200 \mathrm{~V}, 600 \mathrm{~A}$. At the time of this paper study, the $1200 \mathrm{~V}$ device was not available, and the model parameters were calculated by 
interpolating from lower power device models. The item, other losses, for ACRDCL inverter includes the clamping device and resonant inductor losses, and for CMRP inverter, it represents the clamping diode loss.

Table 1: Inverter efficiency comparison at the rated output

\begin{tabular}{|lcc:c|}
\hline & SPWM (20kHz) & AC-RDCL (65 kHz) & CM-RP (20 kHz) \\
\hline Input ( $\mathrm{kW})$ & 55.1 & 54.3 & 60.3 \\
\hline Output $(\mathrm{kW})$ & 52.0 & 52.0 & 52.0 \\
\hline Efficiency (\%) & 94.3 & 95.7 & 86.2 \\
\hline Total losses (W) & 3,148 & 2,323 & 8,353 \\
Cond. losses (W) & 1,408 & 1,737 & 6,660 \\
switches & 1,221 & 1,506 & 5,758 \\
\hline diodes & 187 & 231 & 902 \\
\hline Switching losses (W) & 1,739 & 11 & 0 \\
\hline turn-on & 869 & 0 & 0 \\
\hline turn-off & 823 & 11 & 0 \\
diodes & 47 & 0 & 0 \\
Other losses & 0 & 575 & 1,693 \\
\hline
\end{tabular}

\section{Conclusions}

The inverter efficiency profiles for different motor speeds and torques have been evaluated. The evaluation results were compared for two soft switching inverters and a traditional hard switching inverter. Using the hard-switching SPWM inverter as the base line, the ACRDCL inverter shows better efficiency over the entire load range. However, the $A C R D C L$ inverter requires higher voltage devices and an additional clamping circuit, increasing the inverter cost. The CMRP inverter, showing poor efficiency over the entire load range especially under low load operations, will not be acceptable in most variable speed motor drive applications. If the motor runs mostly in low speed conditions, the CMRP inverter is even more unacceptable. Overall, both soft switching inverters show some disadvantages in motor drive applications, either high cost or low efficient. Other opportunities may be corsidered to improve the soft switching inverters for practical applications. The following lists are some examples for further studies.

1. The auxiliary switch resonant transition inverter may be a candidate ic out-perform both soft-switching inverters that were evaluated in this paper.

2. The constant voltage drop devices like the MOS Controlled Thyristors (MCTs) may be used in CMRP inverters to improve the efficiency to an acceptable range because the thyristor device does not contain ohmic drop that is objectionable in high circulistion current conditions.

3. Using non-linear resonance or multiple-tune resonant circuits for non-linear resonance may improve performance and efficiency of both RDCL and CMRP inverters. 


\section{References}

[1] D. M. Divan, G. Venkataramanan, and R. W. DeDoncker, "Design Methodologies for Soft Switched Inverters," in Conference Record of IEEE LAS Annual meeting, October 1988, pp. 758-766.

[2] D. M. Divan, G. Venkataran anan, and R. W. DeDoncker, "Design Methodologies for Soft Switched Inverters," IEEE Trans. on IAS, Vol. 29, No 1, Jan./Feb. 1993, pp. 126135.

[3] D. M. Divan and G. Skibinski, "Zero Switching Loss Inverters for High Power Applications," in Conference Record of IEEE LAS Annual meeting, October 1987, pp. 627-634.

[4] G. Venkataramanan, and D. M. Divan, "Pulse Width Modulation with Resonant DC Link Converters," in Conference of IEEE LAS Annual Meeting, Oct. 199.0, pp. 984-990.

[5] A. Cheriti, K. Al-Haddad, L. A. Dessaint, T. A. Meynard, and D. Mukhedkar, "A Rugged Soft Commutated PWM Inverter for AC Drives," IEEE Trans. on Power Electronics, Vol. 7, No. 2, April 1992. pp. 385-392.

[6] H. Yonemori and Nakaoka, "Advanced Soft-Switching Sinewave PWM High-Frequency Inverter-Link Cycloconverter Incorporating Voltage-Clamped Quasi-Resonant and Capacitive Snubber Techniques," in Conference Record of IEEE Power Electronics Specialists Conference, June 1991, 795-802.

[7] S. Clemente and B. Pelly, "An Algorithm for the Seiection of the Optimum Power Device for the Electric Vehicle Propulsion," in Proceedings of IEEE Workshop on Power Electronics in Transportation, Oct. 1992.

\section{Figures:}

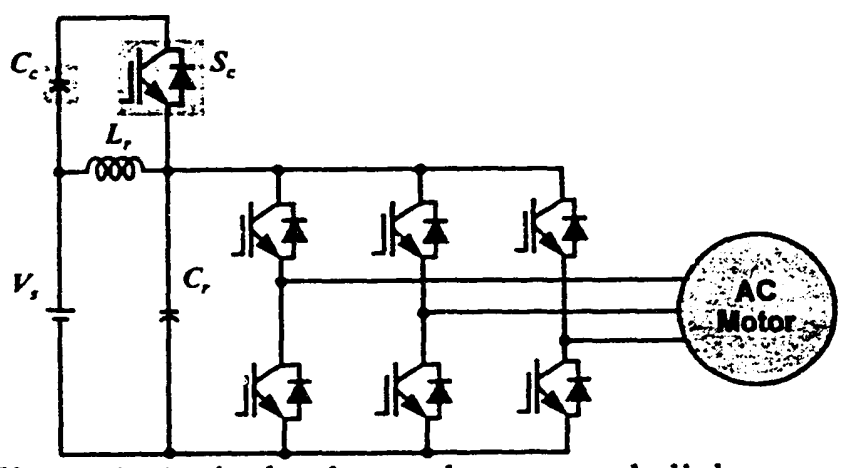

Figure 1: Actively clamped resonant dc link inverter.

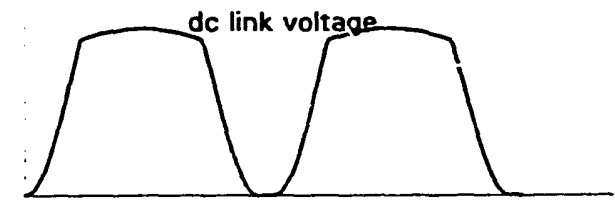

Figure 2: The dc link voltage across the inverter input 


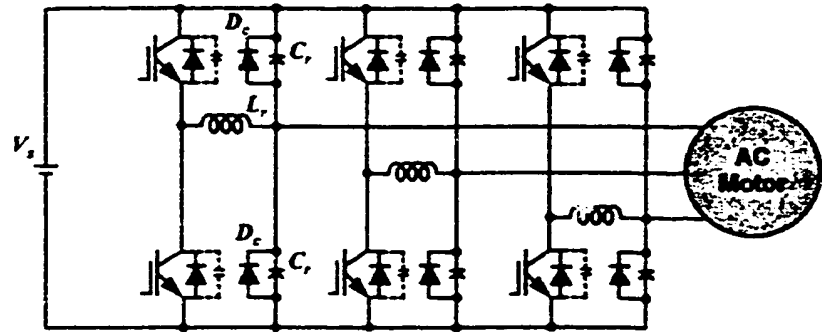

Figure 3: Clamped-mode resonant pole inverter.

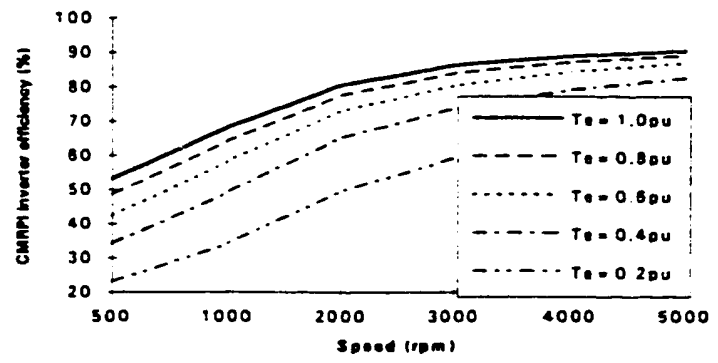

Figure 5: Clamped mode resonant pole inverter efficiency as a function of speed and torque

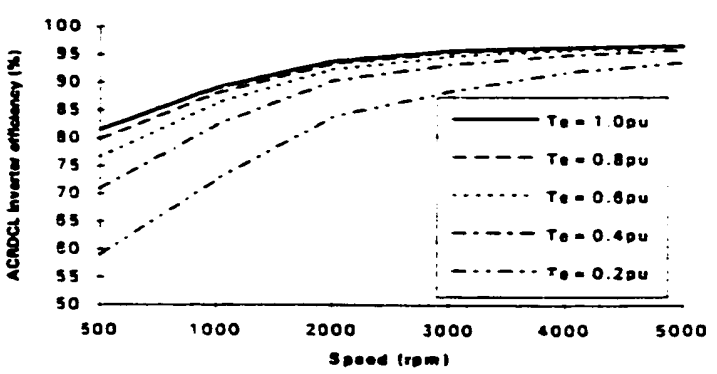

Figure 4: ACRDCL inverter efficiency as a function of speed and torque

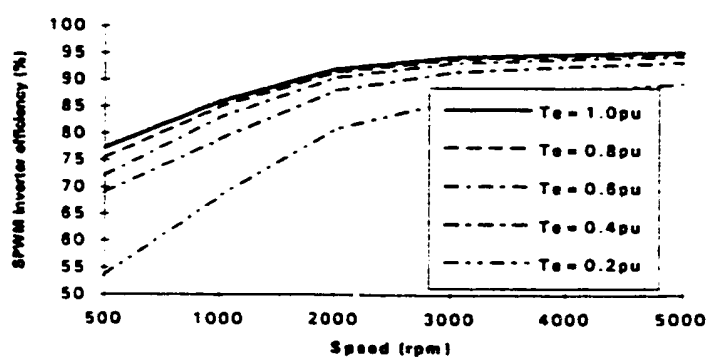

Figure 6: SPWM inverter efficiency as a function of speed and torque

\section{Appendix A: Induction Machine Parameters and Its Output Characteristics}

\section{A-1 Motor Parameters and Specifications}

Stator resistance $=$

$12.9 \mathrm{~m} \Omega$

Rotor resistance $=$

$12.5 \mathrm{~m} \Omega$

Stator leakage inductance $=$

$72.62 \mu \mathrm{H}$

Rotor leakage inductance $=$

Core loss resistance $=$

$76.08 \mu \mathrm{H}$

Magnetizing inductance $=$ $36 \Omega$

Rated speed $=$

$1195.5 \mu \mathrm{H}$

Rated torque $=$ $3000 \mathrm{rpm}$

Pole $=$ $160 \mathrm{nt}-\mathrm{m}$

Line-to-line voltage $=$ 6 $208 / 240 \mathrm{~V}$

\section{A-2 Motor Output Characteristics Under Field-Oriented Controlled Operation}

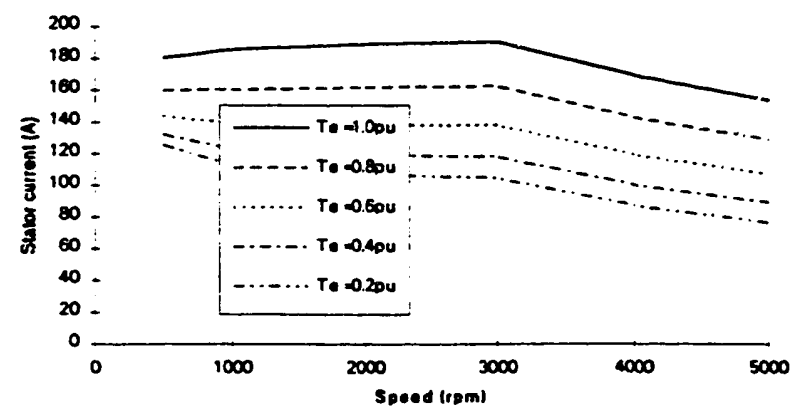

Figure A.1: Motor stator current (rms value) as a function of speed and torque.

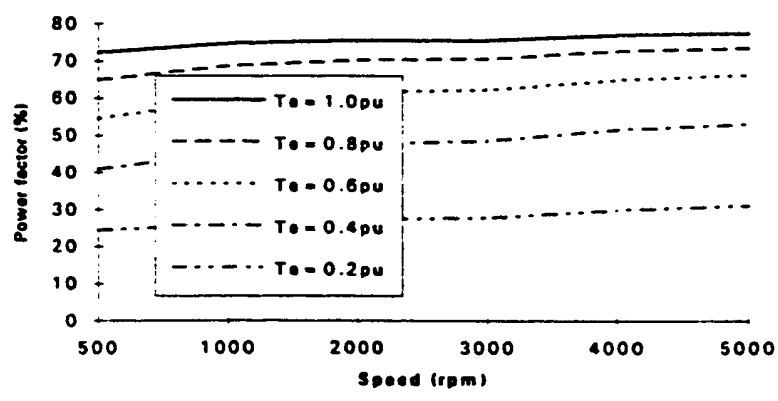

Figure A.2: Motor input power factor as a function of machine speed and torque. 


\section{Appendix B: Operation Modes of the Clamped Mode Resonant Pole Inverter}

Using a single-phase full bridge circuit, the operation modes of the clamped mode resonant pole inverter can be explained in Figures B.1 B.3. Assume that the initial load current is flowing in positive direction, but the resonant inductor current is free-wheeling through the main switches' anti-paralleled diodes. The switches will be operated under zero-voltage current condition because the resonant inductor always circulates a negative current through the oncoming switches.

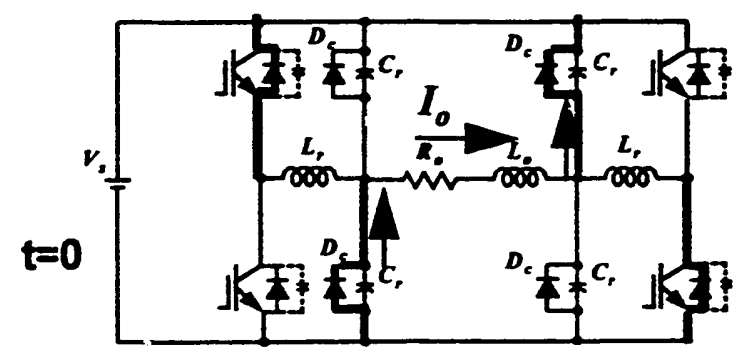

Figure B.1: A single-phase full bridge CMRP inverter and its initial condition.

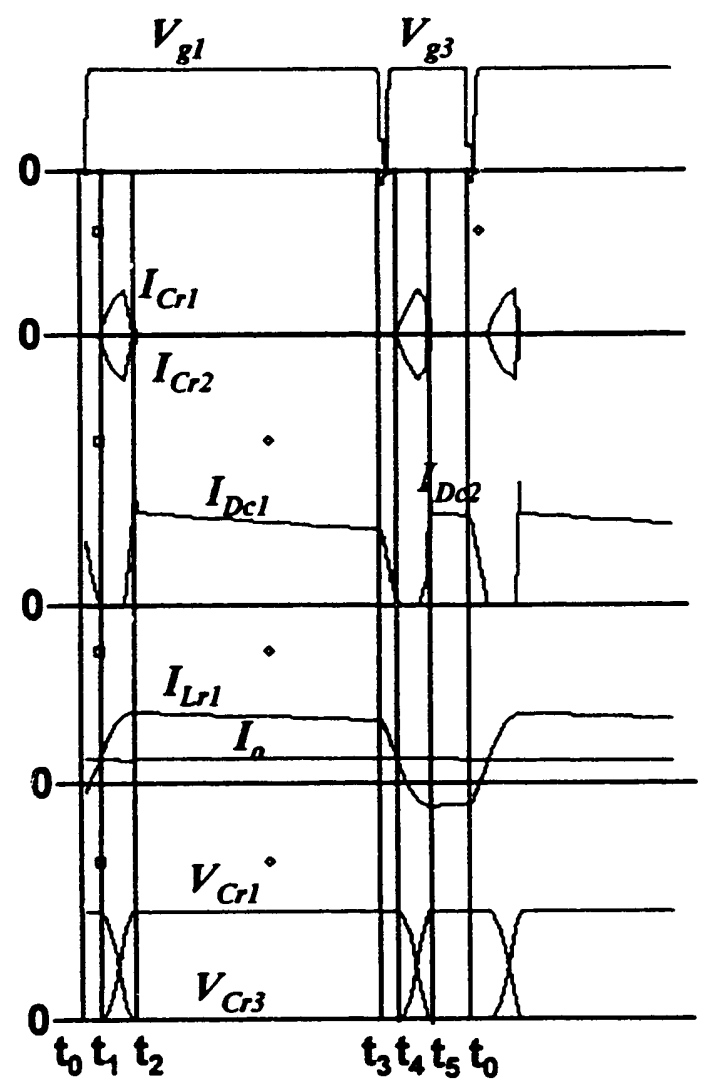

Figure B.2: Current and voltage waveforms during one switching cycle operation. 


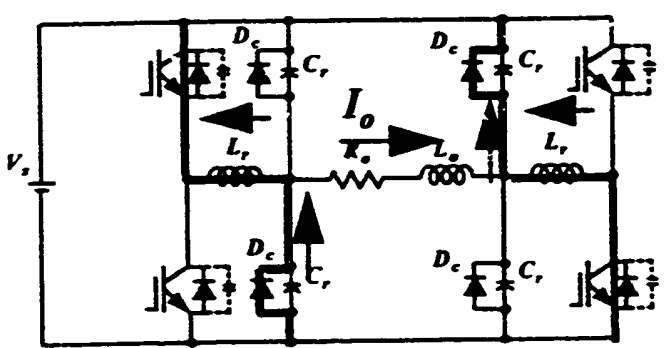

(a) mode 1: $t_{0}<t<t_{1}$

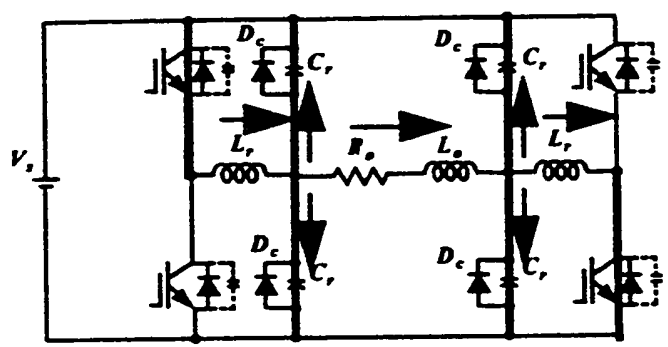

(b) mode 2: $t_{1}<t<t_{2}$

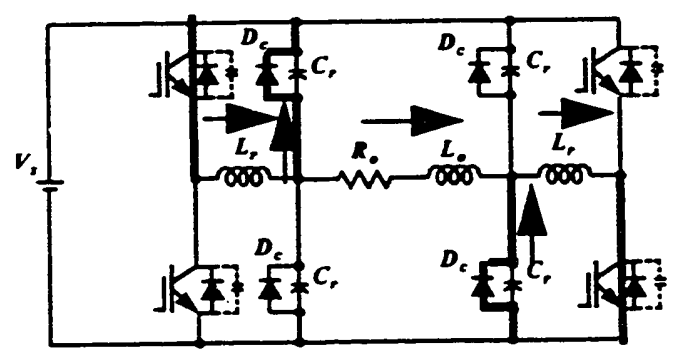

(c) mode 3: $t_{2}<t<t_{3}$

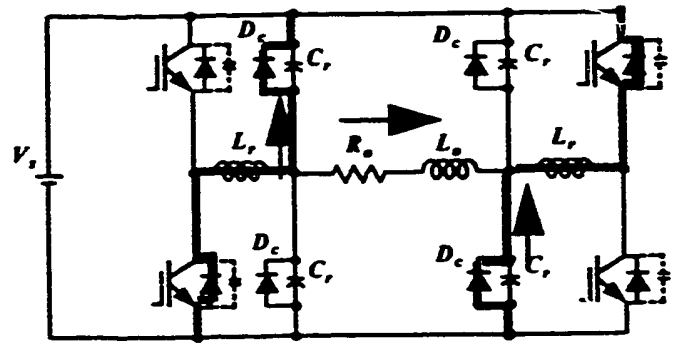

(d) mode 4: $t_{3}<t<t_{4}$

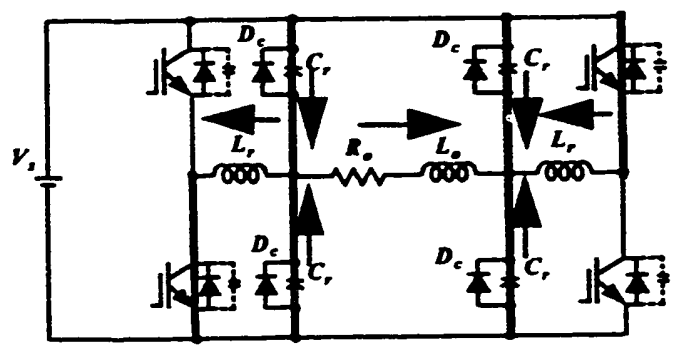

(e) mode 5: $t_{4}<t<t_{5}$

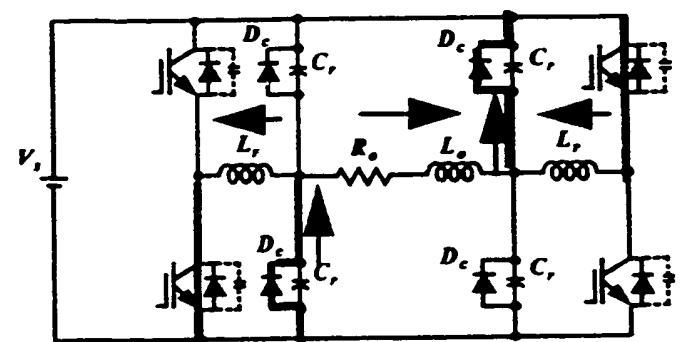

(f) mode 6: $t_{5}<t<t_{0}$

Figure B.3: One switching cycle operation modes of the single-phase full bridge CMKP inverter. 

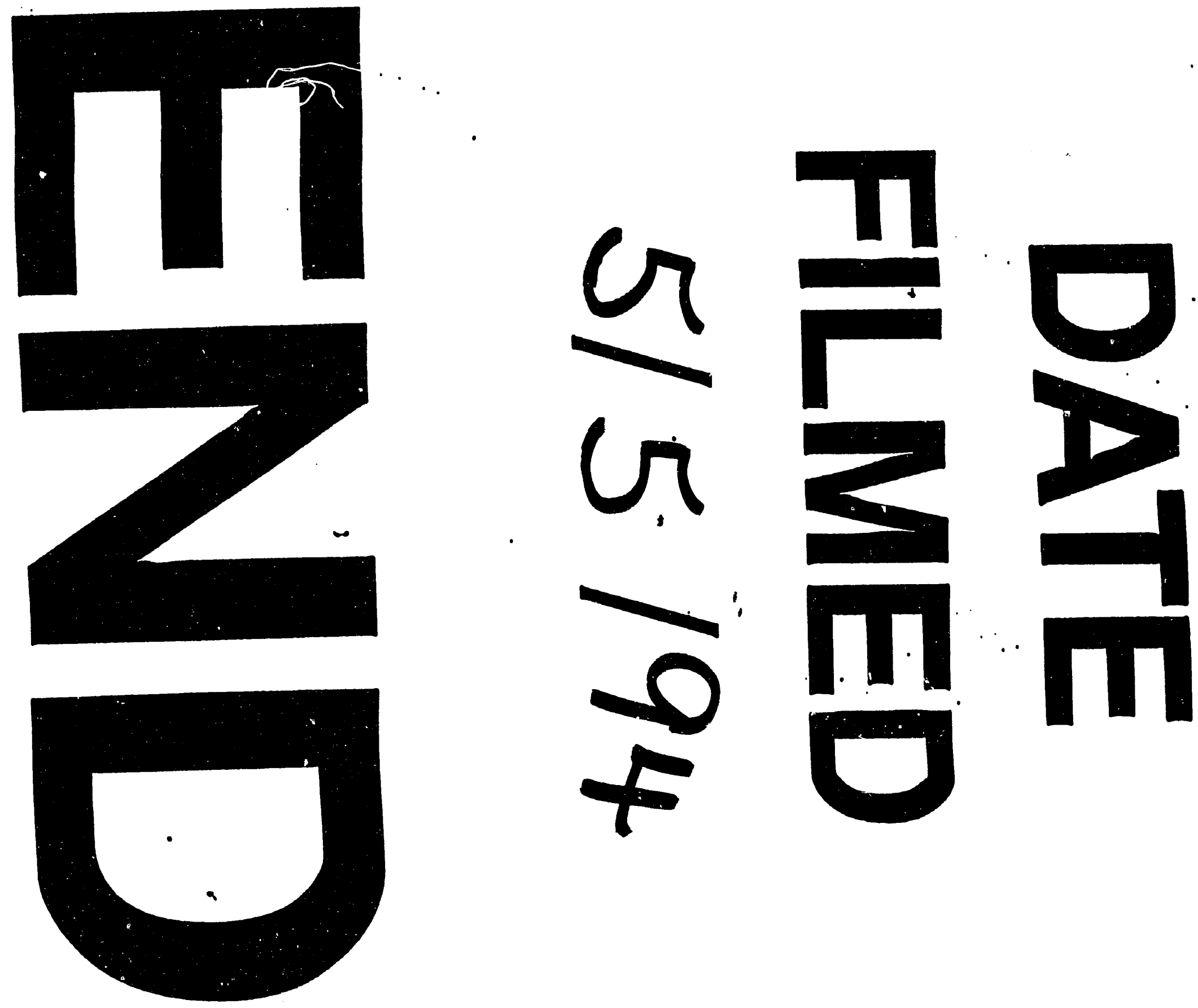